\title{
Independence of central controls of vascular and sweat gland responses in the paw of the cat
}

\author{
B. J. PROUT, J. H. COOTE, AND C. B. B. DOWNMAN \\ From the Department of Physiology, Royal Free Hospital School of Medicine, London
}

The galvanic skin response can be recorded as a reduction of skin resistance (Féré, 1888) or as a change of skin potential (Tarchanoff, 1890). Accompanying this response there may occur a vasoconstriction of the digits, shown by reduction of volume, pulsation, and blood flow. In the past there has been discussion about the relationship between the electrical and the vascular events. Recently Lader and Montagu (1962) have used pharmacological blockades to separate the responses in man, and have shown that each may occur when the other response is blocked. Their findings imply that the peripheral pathways are separate and independent in the post-ganglionic section. This still leaves open the question whether the pathways and controls are distinct within the central nervous system.

The purpose of this paper is to report findings which show that the responses can be elicited separately when activating the central paths by direct or reflex stimulations. The central controlling pathways, both excitatory and inhibitory, are individual at least up to medullary level.

\section{METHODS}

Cats of $2 \cdot 2$ to $3 \cdot 3 \mathrm{~kg}$. were anaesthetized with a chloraloseurethane solution $(35 \mathrm{mg}$. and $700 \mathrm{mg}$. respectively per $\mathrm{kg}$. body weight) intraperitoneally; supplements of the mixture equivalent to $5-10 \mathrm{mg}$. chloralose were given intravenously at intervals to maintain or deepen anaesthesia (Wang and Brown, 1956). The galvanic skin response was recorded as the voltage change between two Ag discs of $5 \mathrm{~mm}$. diameter. One disc with Cambridge electrode jelly on the contact face was strapped on to the surface of the central pad of the paw; the other, indifferent, electrode was stitched under the skin of the dorsum of the same foot. Voltage changes were recorded with a Grass 5P1 preamplifier (time constant $0.8 \mathrm{sec}$.). Paw volume was recorded by inserting the shaved paw into a glass plethysmograph, and making an airtight seal with strips of vaseline-soaked lint. The plethysmograph was connected by tubing to a Grass PT5A low-pressure transducer, which responded to volume changes of the paw. Decreases of paw volume with decrease of pulsation indicated vasoconstriction of the pads (Downman,
Goggio, McSwiney, and Young, 1943), while the converse changes indicated vasodilatation. The volume changes were of the order of 5 to $10 \mathrm{~mm}^{3}$, or up to twenty times the amplitude of the baseline pulsation; active and passive changes were distinguished by recording the arterial pressure through a polythene cannula in the central end of a cut carotid artery, filled with $0.9 \% \mathrm{NaCl}$-heparin solution and connected to a Statham P 23 Ac transducer. Breathing was recorded by intra-oesophageal balloon and Grass PT5A transducer. All transducers were used in conjunction with Grass 5P1 amplifiers, and recordings were made on a Grass model 5 six-channel pen-recording polygraph.

Galvanic skin response and paw volume changes could be elicited as reflexes by stimulating the central end of a superficial radial nerve. Square pulses of 1 to $3 \mathrm{msec}$. duration, 1.5 to $15 \mathrm{~V}$, were applied as single shocks or at $100 / \mathrm{sec}$. for 0.25 to $1 \mathrm{sec}$.

To stimulate within the brain-stem the cat's head was held in a stereotaxic device and tilted $45^{\circ}$ nose down in relation to the Horsley-Clarke horizontal plane. The vertical unipolar electrode could be inserted avoiding the tentorium cerebelli. A stereotaxic coordinate map of the brain-stem in the $45^{\circ}$ plane had been previously prepared. The stimulating electrode was a $25 \mu \mathrm{Pt}$. wire sealed in a glass capillary tube with varnish; total diameter was 150 to $300 \mu$ and resistance approximately $5 \mathrm{~K} \Omega$. The other electrode was a Pt. plate attached to the reflected temporal muscle, and the cat was earthed through another Pt. plate buried under the skin of the trunk. The stimulating electrode was thrust into the brain-stem through holes drilled in the cranium, advancing in 0.5 $\mathrm{mm}$. steps. Negative-going square pulses of 0.5 or 1.0 msec. duration, 50 to $200 / \mathrm{sec}$. for 10 to $15 \mathrm{sec}$. were limited to $3 \mathrm{~V}$. maximum strength. They were delivered to the unipolar electrode through a transistorized R.F. coupling unit (Adams and Prout, 1962).

During the experiment the stimulus sites were chosen by reference to the standard map of the brain-stem. At the end of the experiment the animal was killed by injecting excess of Na-pentobarbitone intravenously. The brainstem was widely exposed and fixed overnight in situ with surrounding $10 \%$ formalin saline with two marker needles in the plane of insertion. Fixation was completed by leaving the isolated brain-stem in formalin saline. Subsequently serial frozen sections were cut in the plane of the electrodes and stained by Weil's method to show the site and depth of the electrode tracks. 

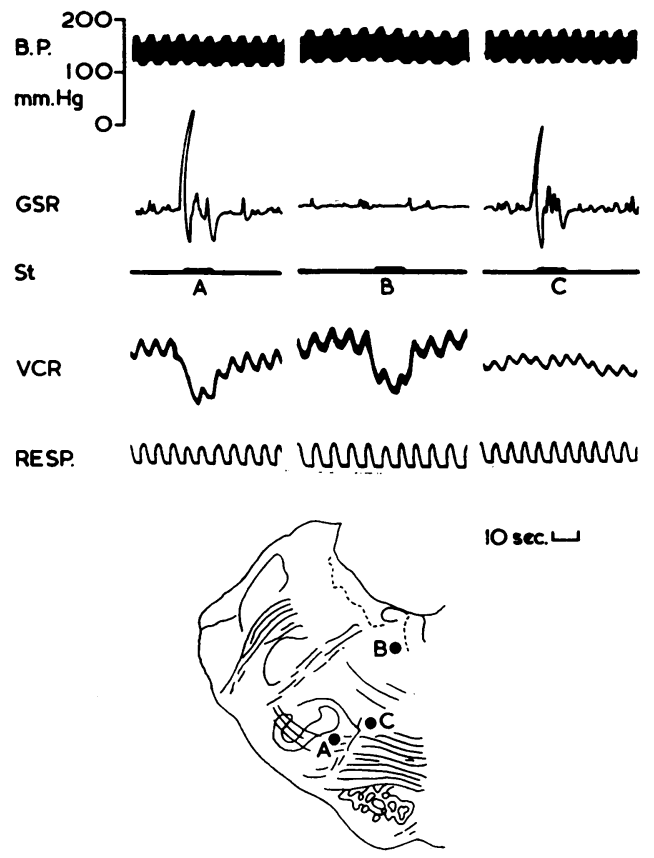

FIG. 1. Stimulation at points in upper medulla causing different combinations of vascular and sweat gland (G.S.R.) responses. Traces from above downward: arterial pressure, galvanic skin response of left hind paw, stimulus marker, volume of left hind paw (constriction downwards), breathing (inspiration upwards). Signal marker shows periods of stimulation at 100/sec. at the points $\mathrm{A}, \mathrm{B}$, and $\mathrm{C}$ in the cross-section diagram. Methods of recording described in text.

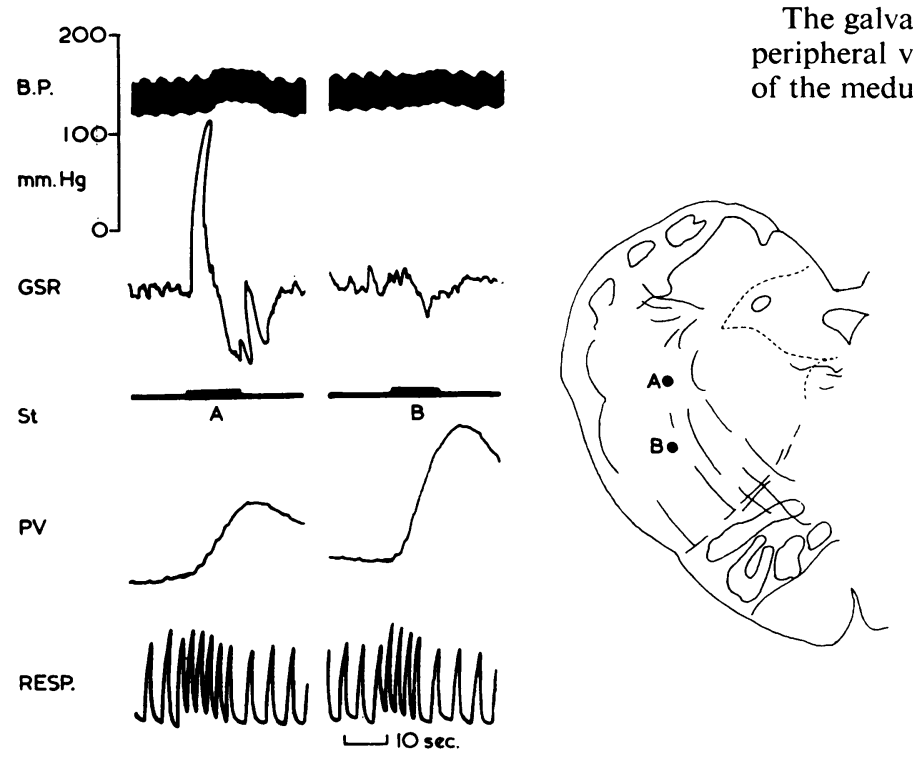

RESULTS

Unipolar stimulation within the bulbar reticular substance in sensitive regions produced both sweat gland and vasoconstrictor responses of the paws. At the same time changes of heart rate, arterial pressure, and breathing might also be elicited. It was found that the paw responses could occur independently of these other responses. Weaker stimulations could produce galvanic skin and vasoconstrictor responses without changes in the other indices. There was difficulty in interpreting a paw volume change if there was at the same time a marked change in arterial pressure which could cause a passive change in volume. Volume changes were considered to be due to active changes in paw vessels when pressure changes were absent or opposed the volume change, or when the volume changes in a series were in different proportions to any accompanying pressure changes.

RESPONSES OF BULBAR ORIGIN Stimulation at points within the medulla showed that the paw responses could be evoked together or separately, depending $\omega$ on the site and strength of the stimulus. In the्ष N experiment of Fig. 1 stimulation at three places inR the medulla caused different combinations of rę sponses. Stimulation at A caused both galvanic skipe $\vec{C}$ and vasoconstrictor responses. From B a similan change of paw volume was obtained without thष्ठ galvanic skin response. From $\mathrm{C}$ a galvanic skim. $\vec{\bullet}$ response was obtained without any change in paw volume. During each of the stimulations there was no significant change of breathing or arterial pressure.

The galvanic skin response will also accompany a peripheral vasodilatation resulting from stimulation of the medulla. In the experiment of Fig. 2 stimula-

FIG. 2. Stimulation of points in medulla at level of the obex, evoking different combinations of galvanic skin response and dilatation of the paw. Traces from above downwards: arterial pressure, galvanic skin response of left paw, stimulus mark, paw volume (dilatation upwards), breathing (inspiration upwards). Stimulus marks $\mathrm{A}$ and $\mathrm{B}$ indicate periods of 100/sec. stimulation at points $\mathrm{A}$ and $\mathrm{B}$ respectively, shown in cross-section diagram of brain-stem. 
tion at $\mathrm{A}$ caused increase of paw volume together with a galvanic skin response. Stimulation at B caused a greater increase of paw volume without galvanic skin response. The change of paw volume involved a vasodilatation of nervous origin since it was not in proportion to the rises of arterial pressure recorded at the same times.

REFLEXLY-EVOKED RESPONSES Stimulating a sensory nerve (superficial radial nerve of forearm) caused both vasoconstrictor and galvanic skin responses in the paws of the other limbs. At times during the same experiment either of the responses would occur without the other, in response to the same nerve stimulation and without any other apparent change in the condition of the cat. The cause of this changed responsiveness is central rather than peripheral. In cats in which the lumbar sympathetic chains had been exposed retroperitoneally beforehand, the chains were stimulated with single shocks during a period of spontaneous absence of one or both of the reflex responses. Such stimuli elicited the peripheral responses of both effectors. It was found also that direct stimulation within the medulla, as described above, could cause galvanic skin and vasoconstrictor responses in preparations in which the responses were absent as reflexes. Whatever the central mechanism involved, it can act differentially on the central pathways to block the reflexes separately or together.

When the galvanic skin and vasoconstrictor responses of one paw were elicited as reflexes by repeated constant-strength stimulation they varied in size from time to time. In an experiment the reflexes were elicited at regular 1-min. intervals. Subsequently amplitudes of galvanic skin response were plotted against amplitudes of the corresponding vasoconstrictor response. This gave a wide scatter of points which showed that there was no correlation in size between the responses. This could also be explained by fluctuation of excitability of the reflex arcs involved.

LEVEL OF ANAESTHESIA When the reflexes failed during the course of an experiment, it was found that they would return on deepening the anaesthesia. This was seen when there was no obvious cause of the failure, such as surgical trauma or bleeding. At such times the anaesthesia was slowly deepened by intravenous injections of small quantities (equivalent to $5 \mathrm{mg}$. chloralose) of the choraloseurethane mixture. It was usual for the galvanic skin response to be demonstable in lighter anaesthesia than was best for the vasoconstrictor response. With deeper anaesthesia the vasoconstrictor response returned and its return followed the vasodilatation of the paw which occurred after each injection of the anaesthetic mixture. It was essential for the vascular reflex that the paw vessels were dilated to the maximum, as shown by the baseline pulsations and by a good pink colour in cats with unpigmented pads. When the vasoconstrictor response was still absent under these conditions, a large vasoconstriction could be caused by the injection of 5 to $10 \mu \mathrm{g}$. adrenalin intravenously. Also in cats in which the sympathetic chain was available for stimulation (see above) single shocks evoked constriction. The failure of vasoconstriction in a welldilated paw is to be explained by a failure or constrictor outflow to peripheral vessels which are themselves capable of constriction.

DIFFERENTIAL INHIBITION OF THE REFLEXES The galvanic skin response, when elicited as a reflex, can be inhibited by repetitive stimulation in the ventromedial medullary substance (Wang and Brown, 1956). Also the reflex vasoconstrictor response can be inhibited by similar stimulation (Coote, Downman, and Prout, 1963; Prout, Coote, and Downman, 1964). Recording both responses together on the same paw it was found that unipolar stimulation in the ventromedial medulla could inhibit both responses together. To show this, the reflexes were elicited by single-shock stimulation of the contralateral arm nerve. This was then repeated during a period of stimulation of 10 to $15 \mathrm{sec}$. in the brainstem at $100 / \mathrm{sec}$. The reflexes were either reduced in amplitude or abolished, depending upon the site and strength of stimulation (see also Prout et al., 1964). Since the baseline of the recordings was not changed by stimulation to the brain-stem alone it is evident that the reflexes are reduced by inhibition, not occlusion. What is relevant here is that inhibition of the galvanic skin or vasoconstriction responses could be caused for the one response or the other independently. Stimulating one point in the medulla inhibited the vasoconstrictor response without altering the galvanic skin response. Stimulating another point caused inhibition of the galvanic skin response without change of the vasoconstrictor response (Figs. 3 and 4). In any one experiment it was found that inhibition of the galvanic skin response was caused more frequently and effective points were more widespread than for the vasoconstrictor response.

\section{DISCUSSION}

There has been divided opinion about the relation between the galvanic skin response and the accompanying vascular response. Some have stated that the electrical (galvanic skin) response is a consequence of the vascular change (Féré, 1888; 


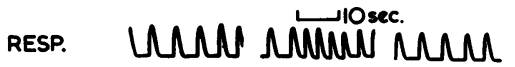
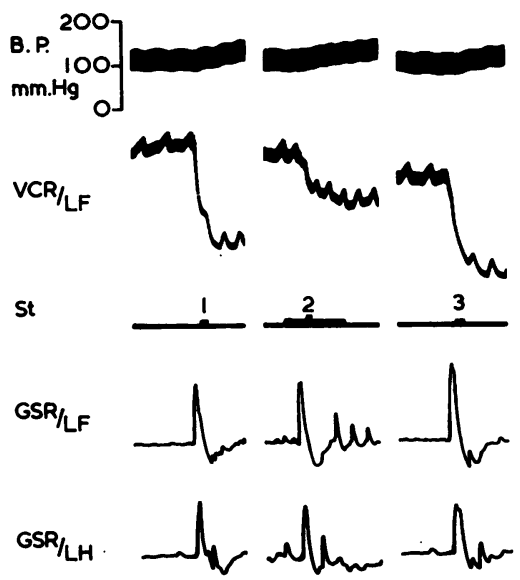

,

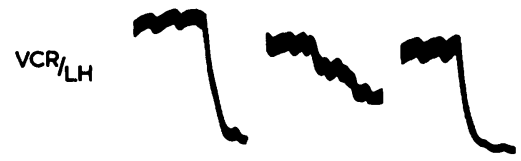

FIG. 3 .

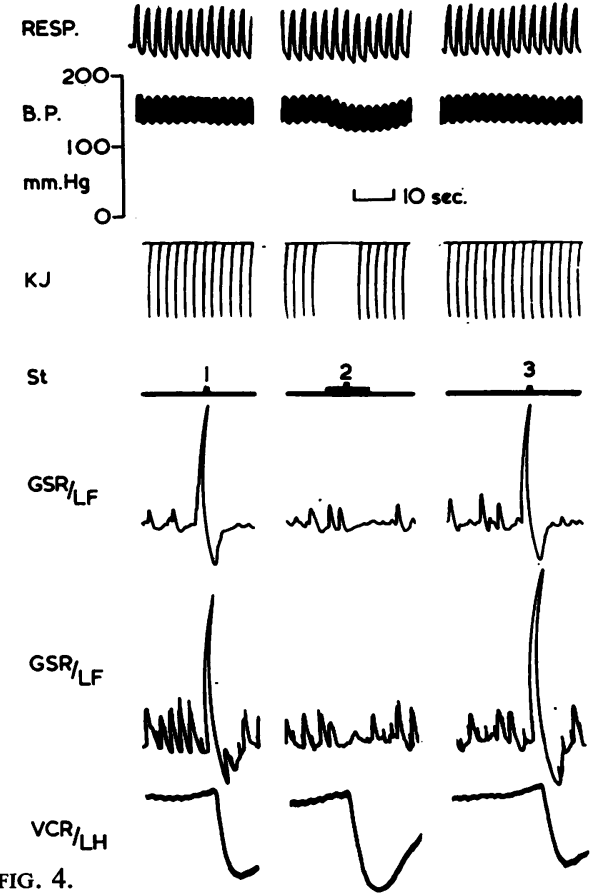

St

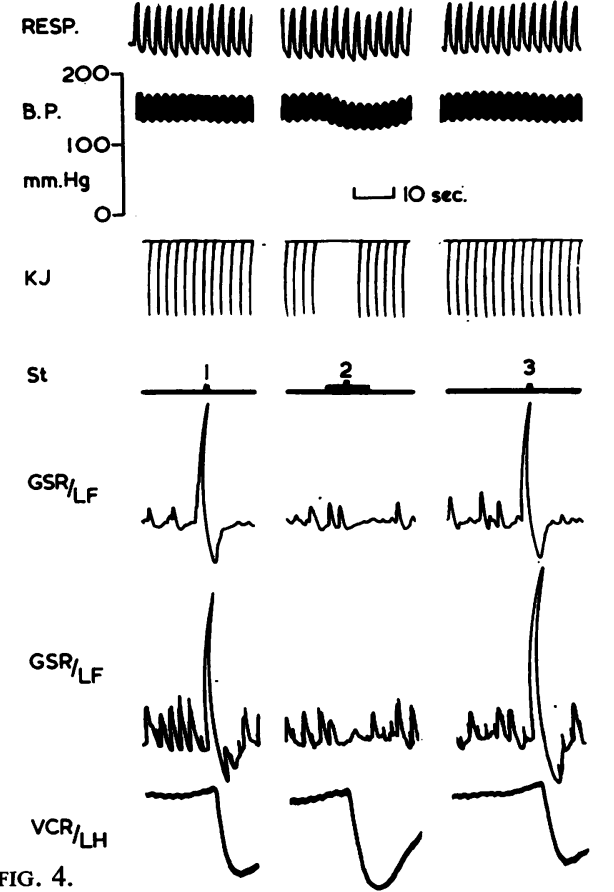

FIG. 4.

FIG. 3. Partial inhibition of vasoconstrictor reflex response (V.C.R.) of paws during intramedullary stimulation withou? effect on galvanic skin response. Tracings from above downwards: breathing (inspiration upwards), arterial pressure volume of left front paw (constriction downwards), stimulus marker, galvanic skin response of left front paw and of lef hind paw, volume of left hind paw (constriction downwards). At signals 1 and 3 brief bursts of repetitive stimulation as contralateral arm nerve elicits reflex galvanic skin and vasoconstrictor responses of both paws. At signal 2 the same. stimulus is given during the marked period of unipolar stimulation in left ventromedial medullary reticular substance (3 V, 1.0 msec. at 100/sec.). Recording details in text. LF and LH refer to left front and left hind paws respectively.

FIG. 4. Inhibition of galvanic skin response during intramedullary stimulation without effect on vasoconstrictor reflex response. Tracings from above downwards; breathing (inspiration upwards), arterial pressure, right knee jerk recording downwards, stimulus marker, galvanic skin response and vasoconstrictor response elicited by brief bursts of repetitive stimulation of contralateral arm nerve. At signal 2 this stimulus was given during the marked period of unipolar stimulation in left ventromedial medullary reticular substance $(0.75 \mathrm{~V}, 1.0 \mathrm{msec}$. at 100/sec.). Recording details in text. Knee jerk elicited by tapping right patellar tendon at $3 \mathrm{sec}$. intervals. LF and LH refer to front and left hind paws respectively.

Vigouroux, 1888; Aveling and McDowall, 1925; Densham and Wells, 1927; Carmichael, Honeyman, Kolb, and Stewart, 1941). Others have considered the galvanic skin response to be a response of the sweat glands which is independent of the vascular reaction (Tarchanoff, 1890; Veraguth, 1906; Darrow, 1929; Landis, 1932). The recent work of Lader and Montagu (1962), involving differential blockades, has shown that the vascular action does not contribute to the initial rapid phase of the galvanic skin response. Their results imply that the post-ganglionic paths for the responses are mutually independent.

The observations reported in this paper provide evidence that there can be independence of action within the central pathways also, at least as high as the medulla. The responses can be evoked separately or together by intramedullary stimulation. The galvanic skin response can accompany constriction or dilatation of the paw. When elicited reflexly the responses fluctuate independently in size. They have different optimal depths of anaesthesia, and they may fail independently although there is no evidence of peripheral failure. By repetitive stimulation in the medullary reticular substance the reflex responses may be inhibited together or separately.

It is a necessary implication of these findings that the post-ganglionic pathways are also separate and independent in action, further confirming the thesis of Lader and Montagu (1962). It must be remembered, though, that this refers to the quick early

\section{吕}


phase of the galvanic skin response. There is also a slower late phase of the galvanic skin response which is seen even in cases where absence of the sweat glands is confirmed (Richter, 1927).

The organization of the central pathways has yet to be defined. The findings could not be explained by assuming two distinct bulbo-spinal pathways activating two types of post-ganglionic fibre. There are also inhibitory pathways which can affect the galvanic skin and vasoconstrictor response mechanisms independently. Although electrical stimulation in the brain-stem is an artificial act which may provoke unusual responses, the results suggest that there are pathways which may also be available to natural stimulations. The independence of the responses evoked as reflexes suggests that they have separate pathways at the segmented level. Variations in amplitude due to spontaneous central changes and to supraspinally-evoked inhibition could well be due to altered conductivity within the spinal reflex arc.

\section{SUMMARY}

In cats anaesthetized with a chloralose-urethane mixture, the galvanic skin response and vascular responses in the pads can occur independently. The responses can be evoked separately or together by intramedullary stimulation. The galvanic skin response can accompany constriction or dilatation of the paw. The responses, when elicited as reflexes, have different optimal depths of anaesthesia and may fluctuate independently in size. Each reflex may fail separately without evidence of peripheral failure. Repetitive stimulation in the ventromedial medullary reticular substance may inhibit the reflexes together or separately. It is concluded that separate bulbospinal pathways are available, and they can be activated independently by stimulations or by neural activity.
This work was supported by grants from the National Institutes of Health, U.S.A. (Grant NB-03171), the Medical Research Council, the Royal Society and the Central Research Fund of the University of London. We are indebted to Mr. N. Thurlow for valuable technical assistance and to Miss F. Ellis for photography.

\section{REFERENCES}

Adams, J. R., and Prout, B. J. (1962). Transistorized R.F.-coupling unit for biological stimulators. J. Physiol. (Lond.), 162, 9P.

Aveling, F., and McDowall, R. J. S. (1925). The effect of the circulation on the electric resistance of the skin. Ibid., 60, 316-321.

Carmichael, E. A., Honeyman, W. M., Kolb, L. C., and Stewart, W. K. (1941). A physiological study of the skin resistance response in man. Ibid., 99, 329-337.

Coote, J. H., Downham, C. B. B., and Prout, B. J. (1963). Supraspinal inhibition of a cutaneous vasoconstrictor reflex. Ibid., 166, 23-24P.

Darrow, C. W. (1929). The galvanic skin-reflex and finger volume changes. Amer. J. Physiol., 88, 219-229.

Densham, H. B., and Wells, H. M. (1927). The mechanism by which the electrical resistance of the skin is altered. Quart. J. exp. Physiol., 18, 175-184.

Downman, C. B. B., Goggio, A. F., McSwiney, B. A., and Young, M. H. C. (1943). Reflex vaso-motor responses of the paw of the cat. J. Physiol. (Lond.), 102, 216-227.

Féré, C. (1888). Note sur les modifications de la résistance électrique sous l'influence des excitations sensorielles et des émotions. C.R. Soc. Biol. (Paris), 40, (8 ser. 5), 217-219.

Lader, M. H., and Montagu, J. D. (1962). The psycho-galvanic skin reflex: A pharmacological study of the peripheral mechanism. J. Neurol. Neurosurg. Psychiat., 25, 126-133.

Landis, C. (1932). Electrical phenomena of the skin. Psychol. Bull., 29, 693-752.

Prout, B. J., Coote, J. H., and Downman, C. B. B. (1964). Supraspinal inhibition of a cutaneous vascular reflex in the cat. Amer. J. Physiol., 202, 303-307.

Richter, C. P. (1927). A study of the electrical skin resistance and psychogalvanic reflex in a case of unilateral sweating. Brain, 50, 216-235.

Tarchanoff, J. (1890). Ueber die galvanischen Erscheinungen in der Haut des Menschen bei Reizungen der Sinnesorgane und bei verschiedenen Formen der psychischen Thätigkeit. Pflügers Arch. ges. Physiol., 46, 46-55.

Veraguth, O. (1906). Die Verlegung diaskleral in das menschliche Auge einfallender Lichtreize in den Raum. Z. Psychol., 42, 162-174.

Vigouroux, R. (1888). L'électricité du corps humain. C.R. Soc. Biol. (Paris), 40, (8 ser. 5), 138-142.

Wang, G. H., and Brown, V. W. (1956). Suprasegmental inhibition of an autonomic reflex. J. Neurophysiol., 19, 564-572. 